the neglect of practical and humane considerations, which are unfortunate by-products of the development of academic psychiatry. Like many clinicians who actually treat patients, I am deeply indebted to Dr. Sargant and his colleagues for their demonstration of the value of MAOI's in phobic states, which has enabled me to help many people who had suffered severe distress over long periods. I am also grateful to them for their courage in pursuing the continued development of combined anti-depressant therapy, in the face of much misguided and irrelevant alarm; this again has brought relief to numerous patients with previously untreatable illnesses.

The pursuit of methodological purity in itself is no guarantee that information of value will result. Some ten years ago, a monumental MRC trial comparing ECT with anti-depressants was a total flop in spite of (or perhaps because of) the weight of scientific sophistication that had gone into its design. About the same time, a study from the Maudsley Hospital 'proved' that phenelzine had no anti-depressant action, a finding which anyone who has had clinical experience of it will find very difficult to accept. At present, we in this area are trying to get the results of four years' experience with long-acting fluphenazine for vulnerable schizophrenics into a form that will be acceptable to academic assessors. Yet this cannot in any way convey the transformation for the better that has been clinically observed in many cases who had previously been subject to continual relapse outside hospital. The day-to-day responsibility for large numbers of severely ill and handicapped people, in ill-equipped and understaffed conditions, is a very different matter from armchair reflections on chisquares, as Dr. Mawson will discover if he ever leaves the academic womb.

Adelphi Clinic, Salford Royal Hospital, Chapel Street, Salford 3 .

\section{DEPRESSION AND CARCINOMA}

DeAR SiR,

In reply to Dr. Judelsohn's letter (Joumal, July 1970, p. 119), which we read with interest, we should like to make the following observations.

The fact that her survey did not bring to light evidence that depressive illness in male patients may be the presenting symptom of carcinoma does nothing to invalidate the observations we made or the conclusions drawn from them. The patients we investigated suffered from a depressive illness that was sufficiently severe to require admission to a psychiatric hospital. The exclusion of relatively mild depressions was unavoidable under these circumstances, but it is irrelevant to the questions at issue.

If Dr. Judelsohn had wished to obtain further evidence bearing on our findings it would have been more appropriate to differentiate between mild and severe depressions in her patients; on the basis of our findings, a prevalence of carcinoma beyond normal expectation would have been predicted only among the severe depressions. Presumably the factual information about the affective states of the patients in her study was not sufficiently detailed to permit such differentiation.

The finding that male patients diagnosed as suffering from carcinoma in a general hospital clinic had a significantly lower prevalence of depression than the control subjects with other types of physical illness suggests interesting possibilities. Those suffering from a malignant disease complicated by severe depression are possibly to be found elsewhere; perhaps in psychiatric hospitals. It is of interest in this connection that two of five patients with carcinoma in our sample had not attended a general hospital clinic, the diagnosis of malignant disease being established only at post-mortem examination.

It cannot be assumed that Dr. Judelsohn's retrospective postal enquiry provides a reliable picture of psychiatric disorder in any selected population. The rate of referral to psychiatric departments of patients with psychiatric disorders from family practice has been shown to vary widely, and differences in prevalence appear unlikely to be the explanation; the amount of interest in, and the degree of alertness to psychiatric disorders are more likely to be involved (Rawnsley and Loudon, 1962). Retrospective studies of psychiatric disorders, even under the most favourable conditions, can provide only an incomplete picture.

T. A. KerR, KURt Schapira, and MARTIN Roth.

Department of Psychological Medicine,

Queen Victoria Road,

Newcastle upon Tyme, $I$.

REFERENCE

RAwnsley, K., and Loudon, J. B. (1962). Sociology Review. Monograph No. 5, University of Keele, 1962.

DIAGNOSIS AND DRUG TREATMENT OF PSYCHIATRIC DISORDERS

DeAr Sir,

Dr. Blackwell's review (I) of our work (5) states '... the author's opinion (is) that diagnosis is the key to treatment. There is nothing in the content of the book to support this view.' If true, this judgment 
would be harsh indeed, since the main thrust of the book, supported by its references, e.g. (2), (3), (4), is that diagnostic prediction of drug effect has been scientifically demonstrated and is clinically valuable.

We venture this protest because our effort was to challenge current diagnostic nihilism by pragmatic validation of drug-relevant diagnostic categories. We regret that Dr. Blackwell found our data and analyses indiscernible.

Donald F. Klein, M.D.

Hillside Hospital, 75-59 263rd Street, Glen Oaks, New York, U.S.A.

\section{References}

1. Blackwell, B. (1970). 'Psychopharmacological doldrums.' British Journal of Psychiatry, 116, 451.

2. KLERN, D. F. (1964).'Delineation of two drug-responsive anxiety syndromes.' Psychopharmacologia, 5, 397-408.

3. - (1967). 'Importance of psychiatric diagnosis in prediction of clinical drug effects.' Archives of General Psychiatry, 16, $118-126$.

4. - (1968). 'Psychiatric diagnosis and a typology of clinical drug effects.' Psychopharmacologia, 13, 359-86.

5. - and DAvis, J. M. (1969). Diagnosis and Drug Treatment of Psychiatric Disorders. Baltimore: Williams and Wilkins.

\section{SECOND CONGRESS OF NEUROLOGY, PSYGHIATRY AND NEUROSURGERY}

Dear Sir,

The Second Congress of Neurology, Psychiatry and Neurosurgery in Bulgaria will be held in Sofia in the first half of October 1971. The First Congress, which took place in October 1967 , owed a considerable part of its success to the wide participation from abroad. Participants from abroad are invited and will be again most welcome at the forthcoming meeting.

The main topics of the Congress will be:

(1) Vascular disorders of the Central Nervous System, (2) Injuries of the brain and the nervous system, (3) Parkinsonism and other affections of the extrapyramidal system.

The Organizing Committee will be grateful if your distinguished journal brings this information to the knowledge of your readers.

Further information should be obtained from:

Professor Ivan Georgiev,

Clinic of Neurology,

Higher Medical Institute,

Sofia 3I, Bulgaria.

DR. T. Stankoushev.

Secretary-in-charge

Prop. G. Savov.

Chairman of the Organizing Committee 